\title{
Akıllı Kent Bileşeni Olarak “Akıllı Vatandaş” Bağlamında Bir Test Sahası Olarak Üniversite Kampüsleri
}

\author{
University Campuses as a Test Field in the Context of "Smart Citizen" as a Component of Smart City
}

\section{Ŏguzhan GÜRSOY}

Uzman, Türkiye Belediyeler Birliği

oguzhan.gursoy@tbb.gov.tr

https://orcid.org/0000-0003-2727-1049
Makale Başvuru Tarihi / Received: 19.04.2019

Makale Kabul Tarihi / Accepted: 06.05.2019

Makale Türü / Article Type: Araştırma Makalesi

\section{Uğur ÖMÜRGÖNÜLŞEN}

Prof. Dr., Hacettepe Üniversitesi, IIIBF,

Siyaset Bilimi ve Kamu Yönetimi Bölümü, HÜYAM,

omur@hacettepe.edu.tr

https://orcid.org/0000-0001-9851-2618

Anahtar

Kelimeler:

Akıllı Kent,

Kuşaklar,

$Z K u s ̧ a \breve{g}_{l}$

Üniversite

Kampüsleri,

Pilot Proje,

Keywords:

Smart City,

Generations,

Z Generation,

University

Campuses,

Pilot Project,
Bu makalenin amacl, kurulum maliyetleri yüksek olan akıllı kent projelerinde pilot uygulama gerçekleştirmenin önemini vurgulamak ve akıllı kentin bileşenlerinden birisi olan "akıllı vatandaş" bileşeni temelinde pilot projeler için üniversite kampüslerinin iyi bir uygulama alanı olabileceğini göstermektir. Bu amaca ulaşmak için ilk olarak toplum ve teknoloji ilişkisi gözetilerek sosyolojik bir analiz olan "kuşaksal farklllıklara" değinilmiş ve üniversitelerin kent ve toplumla olan ilişkisi incelenmiştir. Daha sonra üniversite kampüslerinin akıllı kent projelerinin test edilmesi ve topluma tanttılmast noktasında sahip olduğu avantaj ve dezavantajlar değerlendirilmiştir. Bisiklet ve araç paylaşımı gibi akıllı hareketlik önlemlerinin uygulanması ve akıllı kent kültürünün oluşturulması için en ideal yerlerden birisinin gençlerin hareketlilik sahası halindeki üniversite kampüsleri olduğu sonucuna varılmıştır. 


\section{GIRISŞ}

Akıllı kentler, geleneksel kentlerden farklı olarak enerji, çevre, ulaşım ve kamu hizmetleri gibi kentsel hizmetlerin ekonomiklik, etkinlik ve etkililik temelinde kalitesini ve performansını artırmak için bilgi ve iletişim teknolojilerini ve yeni tarz kentsel planlama ve yönetim ilkelerini araç edinen kentlerdir. Akıllı kent yaklaşımı, bilgi ve iletişim teknolojilerinin belirli bir alana uygulanmasından çok daha fazlasını ifade etmektedir. Buna göre, akıllı kent yaklaşımını ele alırken sadece teknoloji araçlarına odaklanmak ve demografi, kültür, coğrafya gibi unsurları göz ardı etmek baştan itibaren hatalı bir algılamaya ve ardından başarısız bir uygulamaya yol açacaktır.

En temel amacı vatandaşları için yaşam kalitesini yükseltmek; ekonomik, ekolojik ve yönetsel anlamda sürdürülebilir bir kentsel ortam yaratmak olan bu yaklaşım bir takım bileşenlerden oluşmaktadır. Dameri'ye (akt.: Terzi ve Ocakçı, 2017:12) göre 4 bileşen (arazi, insan, yönetim ve altyap1) üzerine kurgulanan akıllı kent yaklaşımı; Avrupa Birliği tarafından 6 bileşen (akıllı ekonomi, akıllı hareketlilik, akıllı yönetişim, akıllı çevre, akı1lı yaşam ve akıllı vatandaş) üzerine inşa edilirken (Uçar vd., 2017:1788); Anthopoulos (2017:8-12) tarafindan 8 bileşen (akıllı altyapı, akıllı ulaşım, akıllı çevre, akıllı hizmet, akıllı yönetişim, akıllı vatandaş, akıllı yaşam ve akıllı ekonomi) üzerine kurgulanmıştır. Görülmektedir ki, bileşen sayısı ve çeşidi kişiye ve kuruma göre değişse de ortak noktalardan birisi "akıllı vatandaş" bileşenidir.

Kentlerin doğa ve insan üzerinde bıraktıkları olumsuz izlerin en aza indirilmesi, nüfus ve kentleşme baskısının kaldırılabilmesi, daha yaşanılır kentler oluşturulması için geliştirilen yeni planlama yaklaşımlarının temel niteliklerini içinde barındıran yeni bir kavram olarak öne çıkan akıllı kent yaklaşımı, aynı zamanda milenyum gençlerinin (Y kuşağı) ve milenyum çocuklarının ( $Z$ kuşağı) kentsel ihtiyaçlarında yaşanan değişime ilişkindir (Sınmaz, 2013:76). Yeni bilgi ve iletişim teknolojilerinin kolaylaştırıcı etkisiyle büyüyen bu kuşaklar, söz konusu teknolojilerin kentsel yaşam alanında da kolaylaştırıcı ve kaliteyi artırıcı bir rol üstlenmesi için beklenti içerisindedir (Adıgüzel vd., 2014:165-178).

$\mathrm{Bu}$ makale, akıllı kent projelerinin büyük bütçeler ile büyük ölçekte gerçekleştirilmeden önce pilot uygulamalarla sınanmasının emek, zaman ve maliyet kayıplarını önleyerek etkinlik ve etkiliği artıracağ 1 varsayımı ile söz konusu pilot projelerin akıllı vatandaş bileşeni bağlamında uygulama alanlarını belirlemeyi amaçlamaktadır. Bu doğrultuda, öncelikle akıllı kent kavramı kuşaksal farklar temelinde ele alınmış ve buradan yola çıkılarak çoğunlukla $Y$ ve $Z$ kuşaklarına ev sahipliği yapan üniversite kampüslerinin akıllı kent projelerinin test edilmesi ve topluma duyurulması hususunda sahip olduğu avantaj ve dezavantajlar değerlendirilmiştir.

\section{KUŞAKLARA İLIŞKİN KAVRAMSAL ÇERÇEVE}

Her bir kuşağın, kendisinden sonra geleni yetiştirdiği ve bilgi, görgü, deneyim ile sonraki kuşağı etkilediği düşünüldüğünde akıllı kentin odağı olan insanların teknolojinin gelişim süreci ile paralellik arz etmesi açısından yaş üzerinden sınıflandırılması gerekmektedir. Yaş üzerinden yapılacak bu sınıflandırma için kuşakları doğdukları yıllara göre tanımlayan sosyolojik analizlerden faydalanmak anlamlı olacaktır.

Türk Dil Kurumu'nun Büyük Türkçe Sözlük’te (2019) tanımladığı üzere yaklaşık olarak yirmi beş - otuz yıllık yaş kümelerine denk gelen nesilleri ifade eden kuşak kavramı, aynı çağın şartlarını yaşamalarından ötürü benzer sıkıntılarla yüzleşen, benzer sorumluluklara sahip olan ve benzer eğilimleri olan kişiler topluluğunun kendilerinden öncekilerden belirgin çizgilerle ayrılmasına dayandırılmıştır. Jenerasyon, öbek, batın ve nesil sözcükleriyle eş anlamlı tutulan kavram bir takım biyolojik, ekonomik, siyasi ve sosyolojik benzerliklere işaret etmektedir. Bu çerçevede varsayımı yapılan belirgin çizgiler 1şığında 21. yüzyıldaki kuşaklar literatürde beş başlıkta sınıflandırılmıştır: Gelenekselciler, bebek patlaması, X, Y ve Z kuşağı (Harber, 2011:5-6; Kırık ve Köyüstü, 2018:1497; Adıgüzel vd., 2014:165). 
Pek çok açıdan benzeşen gelişmelerin bir sonucu olarak müşterek eğilimlere sahip olan bu kuşaklar; kendilerine özgü değer yargılarına, davranışlara ve tutumlara sahiplerdir. Bu durum her bir kuşağa çeşitli güçlü ve zayıf yönler kazandırmaktadır. Literatürde genelgeçer ifadelerle sınırları çizilen bu kuşaklara dâhil edilen bireylerin o kuşağın tüm özelliklerini taşıdığını söylemek güç olsa da kuşaklar genellikle şu özelliklerle ifade edilmiştir:

\subsection{Gelenekselciler}

1922 ve 1945 arasındaki dönemde doğduğu kabul edilen bu kuşaktakilerin günümüzde çalışma yaşamından çekildiği söylenebilir. Doğdukları yıllar itibariyle dünya genelinde yaşanan büyük savaşlara ve ekonomik sorunlara denk gelen bu kuşak tedbir ve tasarruf ile özdeşleşmiştir. ${ }^{1}$ Yazılı iletişim türlerini esas alan bir iletişim metoduna sahip oldukları için bilgi edinme imkânları kısıtlı olan bu kuşaktakiler genellikle otoriteye ve hiyerarşiye uyum sağlamaktadır. Bu sebeple "sessiz kuşak" isimlendirmesi de yapılmıştır (Troksa, 2016:13-14).

\subsection{Bebek Patlaması}

II. Dünya Savaşı sonrasındaki (1946 ve 1964 yılları arası) hızlı nüfus artışı döneminde doğduğu kabul edilen bu kuşaktakiler (baby-boomers) siyasi, sosyal ve ekonomik bir takım iyileşmelere denk gelmişlerdir. Önceki dönemlere oranla lüks harcamaların arttığ 1 bir dönemde yetişen bu kuşaktakilerde bireycilik ve işkoliklik davranışları gözlemlenmiştir. Kuralcı olarak yetişen bu kuşaktakilerin ebeveyn olduklarında ise aşırı korumacı bir tutum sergiledikleri görülmüştür. Bir önceki dönemde altın çağını yaşayan radyo ile birlikte yetişmeleri sebebiyle iletişim ve teknoloji araçlarına önceki kuşağa oranla daha yatkındırlar (Akt.: Williams ve Page, 2011:5).

\subsection{Kuşağı}

1965 ve 1980 yılları arasındaki dönemde doğduğu kabul edilen bu kuşaktakiler bir önceki kuşaktakiler tarafından korumacı olarak yetiştirildikleri için -görece- daha güçlü bağımsızlık ve esneklik davranışları geliştirmişlerdir. Çetin Aydın ve Başol'un (2014:3) Coupland'den aktardığına göre, bu kuşaktakiler kendilerini topluma zıt olarak görmüş ve toplumsal sorunlar karşısında duyarlı davranarak sert politik çıkışlar yapmıştır. Soğuk Savaş ve Petrol Krizi gibi çalkantılarla büyümeleri sebebiyle "yeni kayıp jenerasyon" olarak isimlendirilmişlerdir (Akt.: Palcikova, 2010:13). Kadınların işgücüne daha fazla katılması ve boşanma oranlarının artması sebebiyle geleneksel aile anlayışının değişmeye başladığı bu dönemde yetişenler kişisel bilgisayar, merdaneli çamaşır makinesi ve bantlı teyp gibi birçok teknolojik yeniliği kullanmak zorunda kalmıştır (Fettahlıŏglu ve Sünbül, 2015:32).

\subsection{Y Kuşağı}

1981 ve 2000 yılları arasındaki dönemde doğduğu kabul edilen bu kuşaktakilerin öncekilerden en büyük farkı teknolojiyle gönüllü bir ilişki içerisinde olmalarıdır (Altuntuğ, 2012:206). "Milenyum Kuşağı" olarak da isimlendirilen bu kuşak sosyolojik ve demografik bir takım etkenlerin sebebiyle (hem annenin hem babanın çalışması, yalnızlık duygusu vb.) internet ile olan gönüllü ilişkileri neticesinde kendilerine sanal yaşam alanları oluşturmuştur. Saymaz (2004) tarafından çoğu o dönem lise çağlarında olmaları sebebiyle "özgür ama yalnız liseliler" olarak tanımlanan bu kuşak hemen tüketmeyi alışkanlık edinen, sabırsız, girişimci, modasever ve bürokrasiden hoşlanmayan bir kuşak olarak betimlenmiştir. Bilgisayar ve internet çağının içine doğan bu kuşak şu andaki yaşları itibariyle "farkl etnik kökenler ve kültürlerden bireyler ile günlük etkileşimi en yüksek olan kuşaktır ve üyeleri önceki kuşaklara göre çok daha fazla kültürel zenginliğe sahiptir" (Çetin Aydın ve Başol, 2014:4). Bu sebeple de "ilk küresel jenerasyon" olarak adlandırılmaktadır (Bejtkovsky, 2016:28).

1 Bu alanyazının inşasının Batılı akademisyenler tarafından gerçekleştirildiği göz önünde bulundurulmalıdır. Zira 1929 Dünya Ekonomik Bunalımı ve İkinci Dünya Savaşı gibi özellikle Batı dünyasını derinden etkileyen iki tarihi olayın kuşaklara olan bakış açısında etkili olduğu görülmektedir. 


\subsection{Z Kuşağı}

Bilgi ve iletişim teknolojilerinde yaşanan hızlı değişim ve gelişim sebebiyle, 2001 ve 2020 yılları arasındaki dönemde doğan/doğması beklenilen bu kuşaktakilerin iletişim anlayışlarının yanı sıra sosyal alışkanlıkları da dijitalleşmiştir. İlk üyeleri şu an üniversitede bulunan bu kuşak bir önceki kuşakta olduğundan farklı olarak teknolojinin içine doğmaktan öte teknoloji bağımlısı haline gelmiştir denilebilir. Mobil bağımlılık, internet bağımlılı̆̆ 1 ve sosyal medya bağımlılığı olarak sayısı artırılabilecek bu bağımlılık çeşitleri bir takım bireysel ve sosyal sorunlara sebep olmaktadır. Öyle ki, birkaç yıl öncesine kadar var olmayan bir olgu ve hastalık olan "FoMO"2 günümüzde bu kuşaktaki bireylerin yaşadığı psikolojik durumla ilişkilendirilmiştir (Baker vd., 2016:275). Kendilerini sözlü olarak ifade etmekten ziyade yazılı olarak ya da görseller ile ifade etmekte daha başarılı olan bu kuşak "internet kuşağı" olarak da isimlendirilmektedir. Yukarıda belirtildiği üzere çeşitli zorluklarla yüzleşen bu kuşak aynı zamanda el, göz, kulak vb. motor beceri senkronizasyonu açısından insanlık tarihinin en başarılı nesli olarak ifade edilmektedir (Akt.: Keleş, 2011:132). İnsanlık tarihi boyunca en fazla doktoralı sayısına ulaşılan günümüz dünyasında psiko-motor öğrenme hızı doğal bir şekilde en gelişmiş olan bu kuşağın tarih boyunca en fazla eğitim almış kuşak olacağı tahmin edilmektedir (Taş vd., 2017:1037).

$\mathrm{Bu}$ kuşak henüz üniversite sonrası çalışma hayatına başlamadığı için kesin yargılar olmamakla birlikte bu kuşaktakilerin markalara ve çalıştıkları organizasyonlara karşı sadakatsiz olabilecekleri, azimli ve hırslı olamayabilecekleri, esnek çalışma ortamları arayacakları, sadece gönüllü oldukları alanda başarılı işler ortaya koyabilecekleri ve iyi bir dinleyici olamayacakları tahmin edilmektedir. Diğer yandan ise teknoloji kullanımı, yenilikçilik, yaratıcılık, takım çalışması, hak arama, özgüven ve farklı sosyolojik gruplara karşı hoşgörülü olma konusunda diğer kuşaklara oranla daha başarılı olacakları düşünülmektedir (Çetin Aydın ve Başol, 2014:4; Harber, 2011:39).

Görülmektedir ki, her kuşağın kendine özgü karakteristik özellikleri, değer yargıları, davranış kalıpları ve birtakım güçlü ve zayıf yönleri bulunmaktadır (Adıgüzel vd., 2014:171). Farklı kuşakların sosyal yaşama ve en temelinde hayata olan bakış açıları ve uyumları, teknoloji alanında da farklılık göstermektedir. Terzi ve Ocakçı (2017:10) tarafından kentlerin geleceği olarak lanse edilen akıllı kentler bir kuşak sonrasında dünyanın gidişatına yön verecek olan $\mathrm{Z}$ kuşağı ile organik bir bağa sahiptir.

Bir yanda Bahçe Kent Hareketi, Komşuluk Birimi, Çağdaş Kent, Toplu Taşıma Odaklı Gelişim, Akıllı Büyüme, Eko-Kent vb. kentsel planlama yaklaşımlarının türevi, diğer tarafta yeni yönetsel yaklaşımın ürünü olan akıllı kentler, hızlı kentsel ve teknolojik gelişmenin bir sonucudur. Bu sebeple, bir kentin akıllılığı, akıllı vatandaş bileşenindeki insanların potansiyeli, yaratıcılığı, siyasal yaşama katılımı ve hoşgörüsü ile doğru orantılıdır. Çünkü bir kente akıllı sıfatını sağlayan şey sahip olduğu teknolojik donanım kadar o teknolojiyi kullanacak insan sermayesinin varlı̆g $ı d_{12}^{3}$.

\section{KAMUSAL BİR SORUMLULUK OLARAK ÖNCE PILOT PROJE UYGULANMASI}

Akıllı kent projelerine dair ekonomiklik, etkililik ve etkinlik gibi teknik performans göstergeleri; işlevsellik, ihtiyaca dönüklük, uygulanabilirlik ve bütünsellik ilkeleri uyarınca test edilmelidir. Akı1lı kent projelerinin öncelikle işlevsel olup olmadığının tespiti ve daha sonra ise performans verilerinin tespiti ile fayda maliyet analizi imkânı sunan pilot projeler deyim yerindeyse kamusal bir sorumluluktur.

Pilot proje, deyim yerindeyse "koşmaktan önce yürümeye benzer" ve yönetsel anlamda sonraki süreçler için kolaylık sağlamaktadır (Haithcoat, t.y.:2). Pilot projelerin sağladığı faydalar genel olarak 8 başlık altında toplanabilir:

2 İngilizce ifadesi "Fear of Missing Out"un (Gelişmeleri Kaçırma Korkusu) baş harflerinin kısaltması olan FoMO, bireylerin sosyal medya ortamlarında gelişmeleri kaçırma ve gelişmelerden haberdar olamama korkusunu ifade etmektedir. Etkinlikler, olaylar ve kişileri takip etme aracı olan sosyal medya bireylere sürekli güncellenen gerçek zamanlı bir bilgi akışı sağlamaktadır. Kolay ve hızlı bir şekilde bilgiye ve kişilere erişme (bazen manipüle edilmiş olsa da) imkânı sunması sebebiyle normal yaşamda sosyal ilişki kurmakta zorlanan kimseler tarafından ilgi ve sevgi edinme noktası olan sosyal medya bireyleri kendisine bağlamaktadır (Kuleli, 2017:1).

3 Bu gerçeklik aslında Türk kentbilim alanının duayeni Prof. Dr. Ruşen Keleş’in çeşitli bilimsel toplantılarda yaptığı konuşmalarda vurguladığı “kentin akıllısı değil, insanın akıllısı olur” ifadesinde de kendini bulmaktadır. 


\begin{tabular}{|c|c|c|}
\hline 1 & Risk Yönetimi & $\begin{array}{l}\text { Pilot proje, başarısızlı̆̆ında söz konusu olduğu bir konuda sınırlandırılmış bir kapasitede uygulama } \\
\text { imkânı sunar. Böylelikle minimum bir yatırım ile risk enaza indirilir ve teknoloji/ürün/hizmet kaynak } \\
\text { israfı olmadan test edilmiş olur. }\end{array}$ \\
\hline 2 & Hizlı Uygulama & $\begin{array}{l}\text { Geliştirilen yeni bir teknoloji/ürün/hizmetin güvenli ve etkili bir şekilde test edilmesi için küçük ölçekli } \\
\text { uygulama yapılması çalışmalara hız kazandıracaktır. }\end{array}$ \\
\hline 3 & $\begin{array}{l}\text { Hedef Kitle ile Test } \\
\text { İmkânı }\end{array}$ & Pilot proje, kullanıcıları seçme imkânı sunar, böylelikle daha doğru uygulama sonuçlarına ulaşılabilir. \\
\hline 4 & $\begin{array}{l}\text { Gerçek Geribildirim } \\
\text { İmkânı }\end{array}$ & $\begin{array}{l}\text { Teoriler ve oyun planları aracılığıyla doğrudan geri bildirim alma imkânı bulunmamaktadır. Pilot } \\
\text { projeler kullanıcıların deneyimlerine ilişkin çıkarımlarda bulunma ve tahmin etme zorluğunu ortadan } \\
\text { kaldırmakta ve doğrudan kullanıcıların deneyimlerini öğrenme firsatı sunmaktadır. }\end{array}$ \\
\hline 5 & $\begin{array}{l}\text { Değişkenleri } \\
\text { Keşfetme İmkânı }\end{array}$ & $\begin{array}{l}\text { Değişkenleri ve geliştirilen stratejileri daha erken ve daha küçük bir kitleyle test etmek daha rasyonel } \\
\text { olacaktır. }\end{array}$ \\
\hline 6 & $\begin{array}{l}\text { Başarısızlıklar ile } \\
\text { Hızlı Yüzleşme }\end{array}$ & $\begin{array}{l}\text { Özellikle yeni geliştirilen teknoloji/ürün/hizmetlerde ilk uygulamalar doğru sonuçlar vermeyecektir. } \\
\text { Basit ve tekrarlayan uygulamalar ile başarı durumunu gözlemledikten sonra çeşitli değişiklikler yapmak } \\
\text { ya da vazgeçmek finansal riski ve zaman kaybını azaltacaktır. }\end{array}$ \\
\hline 7 & $\begin{array}{l}\text { Yeni Fikirleri } \\
\text { Teşvik Etmek }\end{array}$ & $\begin{array}{l}\text { Fikirlerin ve ürünlerin test edilmesi bazen yeni fikir ve ürünlerin keşfedilmesine yol açabilir. Pilot } \\
\text { projeler aynı zamanda inovasyon kültürünün de bir parçasıdır. }\end{array}$ \\
\hline 8 & $\begin{array}{l}\text { Ölçüm Yöntemlerini } \\
\text { Test Etme İmkânı }\end{array}$ & $\begin{array}{l}\text { Bir teknoloji/ürün/hizmetin başarısını belirlememize yarayan performans ölçümü ve fayda-maliyet } \\
\text { analizi gibi metrikler bir tür bilgi sağlama yöntemleridir. Pilot projeler ile sadece teknoloji/ürün/hizmet } \\
\text { değil aynı zamanda metriklerimizde sınanmaktadır. }\end{array}$ \\
\hline
\end{tabular}

Kaynak: Wulfraat, 2017.

$\mathrm{Bu}$ noktada makalenin temel sorusu olan "akıllı vatandaş bileşeni bağlamında akıllı kent pilot projelerini nereden uygulamaya başlamalı?" sorusu gündeme gelmektedir. Bu soruyu yanıtlayabilmek için hılı kentleşme sonucunda mutlak ve oransal büyüklüğe ulaşılması sebebiyle eğitim, sağlık, ulaşım, yeşil alan ve güvenlik gibi kamusal hizmetlere erişimde karşılaşılan sorunlara yönelik olarak üretilen akıllı çözümlerin hangi mekânsal alanlarda daha uygulanabilir olduğunun belirlenmesi gerekmektedir. Organize sanayi bölgesi, üniversite kampüsleri, kamu kurumları, eğlence parkları, tarım alanları, ormanlar, gecekondu bölgeleri ya da kent merkezlerinden hangilerinin akıllı kent çözümü uygulayıcılarına nicel ve nitel anlamda daha rasyonel uygulama alanı sağlayacağının tespiti akıllı kent projelerinin başarısını doğrudan etkileyecektir.

\section{4. “AKILLI VATANDAŞ" BIILEŞENİ BAĞLAMINDA PILOT PROJELERE NEREDEN BAŞLAMALI?}

Diğer kuşaklardan daha farklı beklentilere, alışkanlıklara ve öğrenme biçimlerine sahip olan Z kuşağı, dijital iş görme süreçlerine vakıf olmaları sebebiyle her alanda ciddi bir dönüşüm yaşanacağının sembolü niteliğindedir. Şu an en büyükleri üniversite eğitimine veya iş yaşamına başlayan bu kuşak bilgi ve iletişim teknolojilerine en uyumlu ve hatta onun bağımlısı olan bir kuşaktır. Akıllı kent olarak isimlendirilen bu yeni kentsel yaklaşımda kısa ve orta vadede en temel kullanıcı olması beklenilen bu kuşağın yaklaşımı şekillendirmesi sürpriz olmayacaktır.

Toplumsal gelişimin ana aktörlerinden olan üniversitelerin en temel görevleri bilgi üretmek; meslek edindirmek; toplumun kültür seviyesine katkı sağlamak; gençleri geleceğe ve toplum yaşamına hazırlanmaktır. Kenti biçimlendiren çok sayıda etken olsa da son yıllarda üniversitelerin rolü artmıştır. Üniversiteler yoğun öğrenci ve akademisyen barındırması ve kentsel yerleşimlerde önemli bir alanı kapsamaları sebebiyle bazı avantajlara sahiptir. 


\begin{abstract}
"Üniversitelerin bulundukları kentle ve kent toplumuyla ilişkilerinin gelişmesi kuşkusuz her iki tarafin da yararına olan ve değişen dünya koşullarına paralel olarak yeniden gözden geçirilmesi gereken bir konudur. Bu, gelişmiş batı toplumlarında da "kent-cübbe" ilişkisi (town-gown relationship) deyimiyle sı kça gündeme gelmekte ve üniversiteler artık birer bilim yuvası olmanın ötesinde görevler üstlenmektedir" (Oktay, 2010:7).
\end{abstract}

Jacobs (1961) "topluluklar hiyerarşisi" olarak kabul edilebilecek kentlerdeki sürdürülebilirlik inşasında "toplum" kavramına öncelik verilmesi gerektiğini savunmuştur. Ayrıca sahip olduğu tüm fiziki yapı ve arazi ile üniversite kampüsleri bu hiyerarşinin içerisinde topluma hizmet etmektedir (Akt.: Colding ve Barthel, 2017:4). Üniversiteler; yerel, bölgesel ve ulusal ölçekte sosyal ve ekonomik kalkınmanın şekillenmesinde giderek artan bir öneme sahiptir. Üniversitelerin sürdürülebilir kalkınma ve inovasyon alanlarındaki rolü 5 ana başlikta toplanabilir: Temel araştırmalara katkıda bulunmak, farklı alanlarda var olan bilgileri birbirine uyumlu şekilde entegre etmek, amaç doğrultusunda akademik müfredat geliştirmek, yenilikçi fikirlere alan açmak ve topluluk kat1lımı (Vidican, 2009:131).

Üniversiteler, kentteki konumlarına göre kent üniversiteleri ve kent diş1 üniversiteler olarak iki grupta incelenebilse de bu makalede herhangi bir ayrım yapılmadan tek bir bakış açısı ile ele alınmıştır. Disiplinlerarası bağların kurulmasına imkân veren, yoğun ve genç nüfus barındıran üniversite kampüsleri bir takım mekânsal ve sosyal avantajlara sahiptir. Bu avantajlar aslında akıllı kent pilot projelerinin neden üniversite kampüslerinde uygulanması gerektiğinin cevabıdır.

Öncelikle eğitimli ve genç bir nüfusa sahip olan üniversite kampüsleri aynı zamanda uluslararası bir ortam sunmaktadır. Kendilerine has kültürü olan, formel eğitim ve öğretimin son evresindeki bu araştırmac1, sorgulayıcı, dinamik ve genç nüfusa sahip olması sebebiyle hareketliliğin, mal tüketiminin, atık üretiminin, ekonomik canlılığın ve teknolojik üretkenliğin konusu olan üniversite kampüsleri -görece- değişime ve yeniliğe açıktır. Hızlı toplumsal ve kültürel değişimlerden en fazla etkilenen, belki de bu değişimlere en hızlı uyum sağlayan kesim 18-24 yaş grubunu oluşturan bu kesimdir (Bayhan, 2013:136). Örneğin, kampüslerde geleneksel ulaşım seçeneklerinin yanı sıra ring servisi, bisiklet ve araç paylaşımı gibi farklı ulaşım seçenekleri de bulunmaktadır. Ayrıca kampüslerdeki derslik, kütüphane, yemekhane, spor salonu, konser salonu, öğrenci kulüpleri ve yurt gibi geniş yelpazedeki fiziksel ve kültürel aktivite alanları 24 saat yaşanan bir mekân yaratmıştır. Bu sebeple çok farklı alanlarda pilot proje yürütülmesi mümkündür. Örneğin, Freie Universität Berlin kampüslerinde 200'den fazla bina ile yaklaşı 35 bin öğrenciye ev sahipliği yapmaktadır. Yıllık bütçesi 400 milyon Euro'yu aşan üniversitede 2001 yılında başlatılan kampüs uygulaması ile enerji tüketiminde yaklaşı \% 25 (40 milyon kilowatt saat) tasarruf sağlanmıştır. Bu tasarruf yıllık yaklaşık 3,5 milyon Euro'luk bir parasal karş1lığa sahiptir (Wanke, 2017:27).

21. yüzyıl, entelektüel sermaye ve insan sermayesi yönetiminin ön plana çıktı̆̆ı/çıkacağı bir yüzyıldır. İnsan sermayesi yönetimi, akıllı kent yaklaşımının en önemli zorluklarından birisidir. Zira odak noktada yer alan insan figürü 1skalandığında amacın hâsıl olması mümkün olmamaktadır. Üniversite kampüslerinin bünyesinde barındırdığı insan sermayesi bu sebeple ciddi bir avantaj teşkil etmektedir. Çünkü kampüslere entegre olan araştırma merkezleri, bilim insanları ve öğrenciler; insan sermayesini ve ilişkiler sermayesini beslemektedir. Yaş düzeyi, eğitim durumu ve ihtiyaçları açısından benzerlik gösteren bir kitleye ev sahipliği yapan üniversite kampüsleri kentlere göre daha homojen bir yapıya sahiptir. Bu durum sebebiyle çok boyutlu bir sorun olan sayısal uçurum, üniversite kampüslerinde kentsel alanlara oranla daha az hissedilmektedir. Güvenli internet, uzaktan eğitim, $e$-devlet, görüntülü haberleşme, çevrimiçi ödeme sistemleri, sosyal medya kullanımı ve teknolojik donanım sahipliği gibi konularda en yetkin kuşaklar olan $\mathrm{Y}$ ve $\mathrm{Z}$ kuşaklarına ev sahipliği yapan üniversite kampüsleri teknoloji alanında yürütülen akıllı kent projeleri için iyi bir uygulama alanı sunmaktadır. Genç nüfusun bilgisayar okuryazarlığı, teknolojiye uyum, değişime açıklık, sayısal uçurum ve sosyal medya kullanımı gibi konulardaki potansiyelinin görece daha fazla olduğu söylenebilir. Zira; 
"2013 ve 2016 yılları arasinda yaş grubuna göre internet kullanımı oranları araştırmasina göre tüm yas gruplarında internet kullanım oranının arttığ ve bu gruplar içerisinde interneti sirastyla en çok 16-24 yaş grubunun ve 25-34 yaş grubunun kullandiğg tespit edilmiştir. Turkcell tarafindan 2013 yllında gerçekleştirilen pazar araştırmasına göre ise akıllı telefon kullanımında 25-34 yaş grubundaki kullanım oranının \%71 ile diğer tüm yaş gruplarından daha yüksek olduğu tespit edilmiştir" (Akt.: Gürsoy, 2019:183).

Günümüzde gelişmiş ülkelerde üniversitelerin giderek karmaşıklaşan rollerine verilen önem klasik rollerine verilenden önemden görece daha fazladır. Yüksek düzeyde yenilik yaratma ve yaratılan yeniliklere uyum sürecini kısaltma çerçevesinde üniversiteler hem bilgi tabanlı ekonomiler için hem de bilgi toplumu için olmazsa olmaz kurumsal yapılardır (Seki, 2012:45). İnovasyonun teşvik edildiği üniversite kampüslerinde aynı sorun üzerinde disiplinlerarası çalışma yapılması da daha muhtemel hale gelmektedir. Örneğin, peyzaj tasarımı bölümü kampüs için bölgenin iklimine daha uygun bitkilerin seçilmesi için çalışma yaparken; teknoloji alanındaki bir bölüm akıllı sulama sistemi kurulmasını sağlayabilir.

Üniversiteler, yenilikçi özellikleri ve toplumda öncü rollere sahip olmalarından dolayı sürdürülebilirliğe yönelik uygulamalarıyla toplumda sürdürülebilir bir yaşam biçiminin yaygınlaşmasına katkı sunmayı amaçlamaktadır (Güllü vd., 2012:24-30). Kampüs içerisindeki enerji maliyetlerinin azaltılması; atık ayrıştırma yoluyla geri dönüşümün sağlanması; yaya, ring servisi, elektrikli araç, bisiklet vb. çoklu ulaşım modlarının birlikte kullanılması gibi çevreci uygulamalar aynı zamanda ekonomik kazanç sağlamaktadır. Çevreci akımların siyasallaştığı alanlardan olan üniversite kampüsleri çoğunlukla yaban hayatı da içerisinde barındıran bir ekosisteme sahiptir. Bu yönleriyle üniversite kampüsleri çevre alanındaki sürdürülebilirlik projeleri için en uygun yerleşim yerlerindendir. Örneğin, Michigan Üniversitesi kampüsünde sürücüsüz araçlar ile başarılı bir ring servisi hizmeti verilmektedir (Mcity, 2019).

Üniversiteler görece demokratik, özerk ve katılımeı bir ortama sahiptir. Çeşitli kısıtlamalar ve sınırlı1ıklar olmakla birlikte üniversiteler kurumsal ve yönetişim kapasitesinin daha yüksek olması sebebiyle araştırma ve geliştirme faaliyetlerinde birincil ortak olarak tercih edilmektedir. Özel sektör ve/veya merkezi hükümet kurumları tarafindan üniversitelere proje bazlı olarak mali destekler sağlanmaktadır. Bunun yanı sıra var olan sosyal ortam, $e$-demokrasi ve $e$-katılımcılık uygulamaları için test alanı açısından firsatlar sunmaktadır.

Üniversite kampüsleri, mekânsal olarak sürekliliğin olduğu alanlardır. Altyapı ve üstyapı yatırımları uzun vadelidir ve kampüslerin tarihi dokuları korunmaya çalışılmaktadır. Bu durum üniversitedeki geleneklerin de nesilden nesile aktarılmasını sağlamaktadır. Fiziksel yapılardan, yeşil alanlara; etkinliklerden, geleneklere kadar geniş bir yelpazede devamlılığın var olduğu kampüs alanları süreklilik arz etmektedir. Üniversite kampüslerinin sahip olduğu süreklilik aynı zamanda doğal bir deney ortamı oluşturmaktadır. $\mathrm{Bu}$ yönüyle yaşayan bir laboratuvar işlevi gören üniversite kampüsleri gerçekleştirilen değişikliklerin kabulüne, çıktılarına ve geri dönütlerine ilişkin firsatlar sunmaktadır. Zira devamlılığın var olduğu bir alanda yapılan değişikliklerin gözlemi ve kıyası daha kolay yapılmaktadır. Örneğin, Hacettepe Üniversitesi Beytepe Kampüsü'nde uzun yıllardır var olan, hem kampüse ulaşım zorluklarından hem de öğrencilerin mali ya da sosyal tercihlerinden kaynaklanan otostop kültürü 2016 yılında Üniversite yönetimince yaptırılan (hukuki-yönetsel geçerliliği tartışılır olmakla birlikte) otostop durakları ile desteklenmiş ve öğrenciler bir akıllı kent çözümü olan araç paylaşımı konusunda teşvik edilmiştir. Gerçekleştirilen bu değişiklik sonrasında yapılacak istatistiki bir çalışma ile otostop çeken öğrenci sayısındaki ve bekleme sürelerindeki değişiklik belirlenebilir. 


\section{GENEL DEĞERLENDİRME VE SONUÇ}

Yaşanan hızlı kentsel gelişmenin ve nüfus artışının bir sonucu olarak toplumsal, ekonomik ve çevresel alanlarda birtakım sorunlar ortaya çıkmıştır. Kentlerin doğal çevre ve insan üzerindeki olumsuz baskısını kırabilmek ve hızlı kentleşmenin sebep olduğu verimsizlikleri ve plansızlıkları aşabilmek amacıyla farklı disiplinlerden beslenen akıllı çözümler üretilmiştir. Doğası itibariyle çok disiplinli bir yaklaşım olan akıllı kentte, gelişen teknolojilerin birer araç olarak kullanılması planlanmıştır.

Yatırım maliyeti yüksek olan akıllı kent çözümlerinin uygunluk ve maliyet analizlerini gerçekleştirebilmek ve çıktılarını ölçebilmek amacıyla düşünülen projeler öncelikle küçük ölçeklerde uygulanmaktadır. Pilot uygulama bölgelerinde ulaşılacak sonuçların ve kazanılacak deneyimlerin, sonraki uygulamanın yöntemi, yönetimi ve örgütü üzerinde yapacağı etki göz önünde bulundurulursa pilot bölge seçiminin ne kadar önemli olduğu anlaşılacaktır. Zira varsayımların doğru şekilde gözlemlenebilmesini sağlayacak olan pilot uygulamalar, sonraki adımlar için ise fikirsel altyapı ve uygulama yöntemi açısından bilgilendirici niteliktedir (Güçbilmez, 1964:146).

Y kuşağının en küçüklerinin ve Z kuşağının en büyüklerinin yaşam alanı olan üniversite kampüsleri aynı zamanda akademik ve idari personeli ile farklı kuşaklardan insanları bir araya getirmektedir. Bu yönüyle farklı ihtiyaçları, beklentileri ve alışkanlıkları olan son kullanıcıların yaşadığı alanlardır. Bir kente akıllı sıfatı verildiği gibi bir kampüse de akıllı sıfatı verilebilir. Akı1lı kampüsler, öğrenme olanaklarının iyileştirildiği, teknolojinin ve ekolojinin teşvik edildiği, daha akıllı insanlar yaratmayı amaçlayan mekânsal alanlardır. Yeni fikirler için bir kuluçka merkezi olan üniversiteler, disiplinlerarası işbirliğine de firsat sağlamaktadır. Farklı alanlardaki kültürel ve sosyal faaliyetlere ev sahipliği yapmaları sebebiyle 24 saat yaşayan canlı bir laboratuvar olan kampüsler yeni teknolojilerin ve ürünlerin test edilmesi için uygun bir ortamdır. Ayrıca, gelecek geri dönütler ile girişimciliği ve inovasyonu tetikleyerek çeşitli prototiplerin icat edildiği yerler olması muhtemeldir. Yükseköğretimin doğru şekilde sayısallaştırılması ile kentlerin bilgiye dayalı ekonomiye geçişini sağlayabilecek olan üniversite ortamında en son teknolojileri deneyimleyen öğrencilerin, kent ve üniversite arasındaki karşıllıklı ilişkiyi geliştirmesi beklenmektedir.

Uygulanan akıllı kent çözümlerinin başarıya ulaşabilmesi için altyap1, finansman, yenilikçi işletmeler, bilgi birikimi, fiziksel ve siber güvenlik gibi bir takım ön koşullar bulunmaktadır. Bilişim teknolojisi temelli akıllı kent uygulamaları ne yazık ki zaman zaman siber saldırılara maruz kalabilmekte, yeterli önlemler alınmadığ 1 takdirde kentlerin altyapıları çökertilebilmektedir. Ancak, iyi eğitimli ve yaratıcı vatandaşlara sahip olunması bu ön koşulların hepsinin öncüsüdür. Çünkü akıllı kent yaklaşımının en temel amacı insanın kentsel yaşam kalitesini artırmaktır. Yani akıllı kent çözümleri, insan için insan tarafından yürütülen bir takım iyileştirme faaliyetlerini kapsamaktadır. İyi eğitimli ve yaratıcı vatandaşlara sahip olunması ön koşulu akıllı kent çalışmalarında üniversitelerin rolüne 1 ş1k tutmaktadır. $\mathrm{Bu}$ makalede, üniversitelerin eğitim ve öğretim faaliyetlerinin yanı sıra kampüs ortamının sunduğu mekânsal avantajlarıyla akıllı kentlerin gelişimine sağladığı katk1 üzerinde durulmuştur. $\mathrm{Bu}$ avantajlar kısaca insan sermayesinin kaliteli olması; üretim ve tüketim faaliyetlerinin merkezi olarak canlı bir laboratuvar imkânı sunması; çevre bilinci ve toplumda öncü bir role sahip olması; görece demokratik ve katılımcı bir ortamın olması; alt yapı ve üst yapı açısından sürekliliğe sahip olması olarak siralanabilir.

Üniversite kampüslerinin pilot projelerin uygulanması açısından sahip olduğu dezavantajlar incelenecek olursa, kampüslerin "kapalı bir kutu" gibi olması sebebiyle bazen toplumsal gerçeklerden uzak olduğu söylenebilir. Başka bir ifadeyle, bir üniversite kampüsünde başarılı bir şekilde uygulanabilen bir pilot proje kent ortamında her zaman başarılı olamayabilir. Ayrıca yaş, sosyal medya kullanımı ve kişisel ihtiyaç gibi konularda kente göre daha homojen bir yapıya sahip olan üniversite kampüslerinin kentteki heterojen yapıyı yansıtamayacağı endişesi de bulunmaktadır. Bu avantaj ve dezavantajların karşılıklı ağırlığı üniversite kampüslerinin akıllı kent pilot projelerin uygulanması açısından elverişliliğini belirleyecektir. 


\section{KAYNAKÇA}

ADIGÜZEL, Orhan, BATUR, Zeynep ve EKȘILİ, Nisa (2014), "Kuşakların Değişen Yüzü ve Y Kuşăgl İle Ortaya Çıkan Yeni Çalışma Tarzı: Mobil Yakalılar", Süleyman Demirel Üniversitesi Sosyal Bilimler Enstitüsü Dergisi, S.1(19), ss.165-178.

ALTUNTUĞ, Nevriye (2012), "Kuşaktan Kuşağa Tüketim Olgusu ve Geleceğin Tüketici Profili", Organizasyon ve Yönetim Bilimleri Dergisi, S.4(1), ss.203-212.

ANTHOPOUlOS, Leonidas G. (2017), Understanding Smart Cities: A Tool for Smart Government or an Industrial Trick?, Springer International Publishing, Switzerland.

BAKER, Zachary G., KRIEGER, Heather ve LeROY, Angie S. (2016), "Fear of Missing Out: Relationships With Depression, Mindfulness, and Physical Symptoms", Translational Issues in Psychological Science, S.2(3), ss.275-282.

BAYHAN, Vehbi (2013), "Gençlik ve Postmodern Kimlik Örüntüleri - Üniversite Gençliğinin Sosyolojik Profili: İnönü Üniversitesi Uygulaması", Gençlik Araştırmaları Dergisi, S.1(1), ss.134-157.

BEJTKOVSKY, Jiri (2016), "The Current Generations: The Baby Boomers, X, Y and $Z$ in the Context of Human Capital Management of the 21st Century in Selected Corporations in the Czech Republic", Littera Scripta, S.9(2), ss.25-45.

COLDING, Johan ve BARTHEL, Stephan (2017), "The Role of University Campuses in Reconnecting Humans to the Biosphere", Sustainability, S.9, ss.1-13.

ÇETIN AYDIN, Gülşen ve BAŞOL, Oğuz (2014), "X ve Y Kuşağı: Çalışmanın Anlamında Bir Değişme Var $M \imath$ ?", Electronic Journal of Vocational Colleges, S.4(4), ss.1-15.

FETTAHLIOĞLU, Hatice Seçil ve SÜNBÜL, Mehri Banu (2015), "Tüketici Etnosentrizmi ve Tüketici Husumetinin X, Y, Z Kuşakları Açısından İncelenmesi", International Journal of Academic Value Studies, S.1(1), ss.26-45.

GÜÇBİLMEZ, Erdoğan (1964), "Toplum Kalkınması Pilot Bölge Çalışmaları", Ankara Üniversitesi SBF Dergisi, S.19(03), ss.143-161, http://dergipark.gov.tr/ausbf/issue/3165/44024 (Erişim Tarihi: 09.01.2019)

GÜLLÜ, Gülen, KÖKSAL, Merih Aydınalp ve ŞENGÜL, Hatice (2012), "Dünyada ve Türkiye'de Sürdürülebilir Kampüs Uygulamalart", Kalkınmada Anahtar Verimlilik Dergisi, S.24(284), ss.24-30.

GÜRSOY, Oğuzhan (2019), "Akıllı Kent Yaklaşımı ve Türkiye'deki Büyükşehirler İçin Uygulama İmkânları", Yüksek Lisans Tezi, Hacettepe Üniversitesi Sosyal Bilimler Enstitüsü, Ankara.

HAITHCOAT, Tim (t.y.), "Pilot Project Importance", E-Presentation, University of Missouri Columbia, https://mospace.umsystem.edu/xmlui/bitstream/handle/10355/3098/PilotProjectImportance.pdf?sequence =1\&isAllowed=y (Erişim Tarihi: 05.03.2019).

HARBER, Jeffery G. (2011), "Generations in the Workplace: Similarities and Differences", Electronic Theses and Dissertations, East Tennessee State University Press, USA, Paper 1255, https://dc.etsu.edu/cgi/viewcontent.cgi?article=2446\&context=etd (Erişim Tarihi: 08.01.2019).

KELEŞ, Hatice Necla (2011), "Y Kuşağı Çalışanlarının Motivasyon Profillerinin Belirlenmesine Yönelik Bir Araştırma", Organizasyon ve Yönetim Bilimleri Dergisi, S.3(2), ss.129-139.

KIRIK, Ali Murat ve KÖYÜSTÜ, Sevda (2018), "Z Kuşağı Konusunda Yapılmış Tezlerin İçerik Analizi Yöntemiyle İncelenmesi", Gümüşhane Üniversitesi İletişim Fakültesi Elektronik Dergisi, S.6(2), ss.1497-1518.

KULELI, Saniye (2017), "Sosyal Ortamlarda Gelişmeleri Kaçırma Korkusu (FoMO) ve Sosyal İstenirlik Değişkenleri Arasındaki İlişkinin Lise Öğrencileri Arasında İncelenmesi", E-Dosya, İnönü Üniversitesi, Malatya. http://icits2017.inonu.edu.tr/dosya/1493752862012192100.pdf (Erişim Tarihi: 08.01.2019).

MCITY (2019), "Mcity Driverless Shuttle", University Of Michigan Kurumsal Web Sayfası, https://mcity.umich.edu/shuttle/ (Erişim Tarihi: 28.03.2019).

OKTAY, Derya (2010), "Çă̆daş Üniversite - Kent İlişkisi Nasıl Olmalt?: "Michigan Üniversitesi - Ann Arbor" Modelinin Öğrettikleri", E-Dosya, Doğu Akdeniz Üniversitesi, KKTC, 
https://farc.emu.edu.tr/Old_Website/foa/tr/foa/pages/news/mekanperest/no15/no15.pdf （Erişim Tarihi: 09.01.2019).

PALCIKOVA, Silvie (2010), "Lost Generations in American Literature", Bachelor Thesis, Tomas Bata University, Zlin.

SAYMAZ, İsmail (2004), "Liseli Olmak Zor Zenaat (1)", Radikal Gazetesi, 09.05.2004, http://www.radikal.com.tr/turkiye/liseli-olmak-zor-zenaat-1-710374/ (Erişim Tarihi: 07.01.2019).

SEKİ, İsmail (2012), "Bilgi Yönetişimi ve Üniversite Ekonomisi: Teorik Bir Yaklaşım", Yönetim Bilimleri Dergisi, S.10(19), ss.45-66.

SINMAZ, Serkan (2013), "Yeni Gelişen Planlama Yaklaşımları Çerçevesinde Akıllı Yerleşme Kavramı ve Temel Ilkeleri", Megaron, S.8(2), ss.76-84.

TAŞ, Hacı Yunus, DEMIRDÖĞMEZ, Mehmet ve KÜÇÜKOĞLU, Mahmut (2017), "Geleceğimiz Olan Z Kuşağının Çalışma Hayatına Muhtemel Etkileri", Uluslararası Toplum Araştırmaları Dergisi, S.7(13), ss.1031-1048.

TERZİ, Fatih ve OCAKÇI, Mehmet (2017), "Kentlerin Geleceği: Akıllı Kentler", İTÜ Vakfı Dergisi, S.77, ss.10-12.

TROKSA, Lauren M. (2016), "The Study of Generations: A Timeless Notion Within a Contemporary Context", Undergraduate Honors Thesis, University of Colorado, Colorado (USA).

TÜRK DİL KURUMU (2019), "Büyük Türkçe Sözlük", TDK Yayınları, Ankara. http://www.tdk.gov.tr/index.php?option=com_bts\&view=bts\&kategori1=veritbn\&kelimesec=212015 (Erişim Tarihi: 28.03.2019).

UÇAR, Ahmet, ŞEMŞiT, Sühal ve NEGIZ, Nilüfer (2017), "Avrupa Birliği Akıllı Kent Uygulamaları ve Türkiye'deki Yansımaları", Süleyman Demirel Üniversitesi İktisadi ve İdari Bilimler Fakültesi Dergisi, S.22(KAYFOR 15 Özel Say1s1), ss.1785-1798.

VIDICAN, Georgeta (2009), "The Role of Universities in Innovation and Sustainable Development", Sustainable Development and Planning IV, S.1, 131-139.

WANKE, Andreas (2017), "Sustainable Campus Management at Freie Universität Berlin - Governance and Participation Matter", Handbook of Theory and Practice of Sustainable Development in Higher Education (Ed. W. Leal Filho vd.), Springer International Publishing, Berlin, ss.27-45.

WILLIAMS, Kaylene C. ve PAGE, Robert A. (2011), "Marketing to the Generations", Journal of Behavioral Studies in Business, S.3(3), ss.3-11.

WULFRAAT, Peter (2017), "13 Benefits of a Pilot Project Before Buying", E-Article, Blog: West. https://www.west.com/blog/interactive-services/13-benefits-pilot-project/ (Erişim Tarihi: 05.03.2019). 